\title{
Flexible $\mathrm{C}_{6} \mathrm{BN}$ Monolayers As Promising Anode Materials for High- Performance K-Ion Batteries
}

\author{
Pan Xiang, Sitansh Sharma,* Zhiming M. Wang, Jiang Wu,* and Udo Schwingenschlögl* \\ Cite This: https://dx.doi.org/10.1021/acsami.0c09451 \\ Read Online
}

ABSTRACT: K-ion batteries attract extensive attention and research efforts because of the high energy density, low cost, and high abundance of $\mathrm{K}$. Although they are considered suitable alternatives to Li-ion batteries, the absence of high-performance electrode materials is a major obstacle to implementation. On the basis of density functional theory, we systematically study the feasibility of a recently synthesized $\mathrm{C}_{6} \mathrm{BN}$ monolayer as anode material for $\mathrm{K}$-ion batteries. The specific capacity is calculated to be $553 \mathrm{mAh} / \mathrm{g}\left(\mathrm{K}_{2} \mathrm{C}_{6} \mathrm{BN}\right)$, i.e., about twice that of graphite. The $\mathrm{C}_{6} \mathrm{BN}$ monolayer is characterized by high strength (in-plane stiffness of $309 \mathrm{~N} / \mathrm{m}$ ), excellent flexibility (bending strength of $1.30 \mathrm{eV}$ ), low output voltage (average open circuit voltage of $0.16 \mathrm{~V}$ ), and

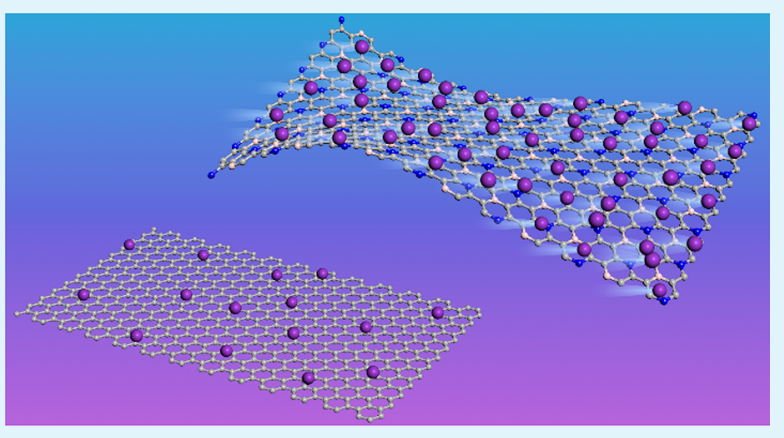
excellent rate performance (diffusion barrier of $0.09 \mathrm{eV}$ ). We also propose two new $\mathrm{C}_{6} \mathrm{BN}$ monolayers. One has a slightly higher total energy $(0.10 \mathrm{eV})$ than the synthesized $\mathrm{C}_{6} \mathrm{BN}$ monolayer, exhibiting enhanced electronic properties and affinity to $\mathrm{K}$. The other is even energetically favorable due to $\mathrm{B}-\mathrm{N}$ bonding. All three $\mathrm{C}_{6} \mathrm{BN}$ monolayers show good dynamical, thermal, and mechanical stabilities. We demonstrate excellent cyclability and improved conductivity by $\mathrm{K}$ adsorption, suggesting great potential in flexible energy-storage devices.

KEYWORDS: energy storage, K-ion battery, flexible anode, $C_{6} B N$ monolayer, first-principles calculation

\section{INTRODUCTION}

The limited reserves of traditional energy sources and the environmental issues caused by them make the development of clean sustainable energy sources an urgent task. ${ }^{1,2}$ However, these sources, such as solar energy and wind energy, are greatly affected by environmental and weather conditions, resulting in fluctuating output. $^{3}$ Therefore, large scale energy storage systems are required that combine safety, stability, and low cost. $^{4,5}$ In addition, emerging electric vehicles and wearable electronics need high performance (high capacity, fast charging) batteries as power source. ${ }^{6-9}$ Regrettably, the current commercial Li-ion batteries are not able to fulfill these demands because of a shortage of Li sources and their uneven global distribution. ${ }^{10,11}$ On the other hand, K-ion batteries can rely on abundant $\mathrm{K}$ sources. In combination with fast ion transport in the electrolyte this makes them to promising alternatives for large scale energy storage systems and electric vehicles. ${ }^{12,13}$ In this context, it is essential to develop for K-ion batteries suitable low cost and high performance electrode materials, as they determine their electrochemical properties.

Interestingly, graphite, the most mature anode material applied in Li-ion batteries, is not suitable for Na-ion batteries but can be used to store $\mathrm{K} .{ }^{14}$ However, because of the larger atomic radius of $\mathrm{K}$ as compared to $\mathrm{Li}$, only one $\mathrm{K}$ atom can be stored per eight $\mathrm{C}$ atoms, corresponding to a specific capacity of $279 \mathrm{mAh} / \mathrm{g} .{ }^{15}$ On the basis of first-principles calculations, the binding energy of a single $\mathrm{K}$ atom on graphene was found to be $1.05 \mathrm{eV}$, which is only slightly larger than the cohesive energy of $\mathrm{K}(0.93 \mathrm{eV})$, indicating potential risk of dendrite formation. ${ }^{16}$ While the electrochemical performance of C-only anode materials is unsatisfactory for $\mathrm{K}$-ion batteries, improvement is found for two-dimensional $\mathrm{C}_{3} \mathrm{~B} .{ }^{17}$ Two-dimensional $\mathrm{C}_{3} \mathrm{~N}$ provides a high specific capacity of $1072 \mathrm{mAh} / \mathrm{g}$, however, only through multilayer adsorption. ${ }^{18}$ For Li-ion batteries the electrochemical performance of ternary B-C-N anode materials (borocarbonitrides) was studied systematically, proposing that $\mathrm{C}$-rich $\mathrm{B}_{0.15} \mathrm{C}_{0.73} \mathrm{~N}_{0.12}$ provides the highest surface area and specific capacity. ${ }^{19}$ Recently, a C-rich borocarbonitride monolayer, $\mathrm{C}_{6} \mathrm{BN}$, could be synthesized using a low cost two-step borylation reaction. ${ }^{20}$ The material combines valley-selective circular dichroism with high carrier mobility, ${ }^{21}$ consistent with the conclusion that higher C content in borocarbonitrides improves the conductivity. ${ }^{22,23}$ This development together with the low mass density and

Received: May 23, 2020

Accepted: June 8, 2020 
(a)

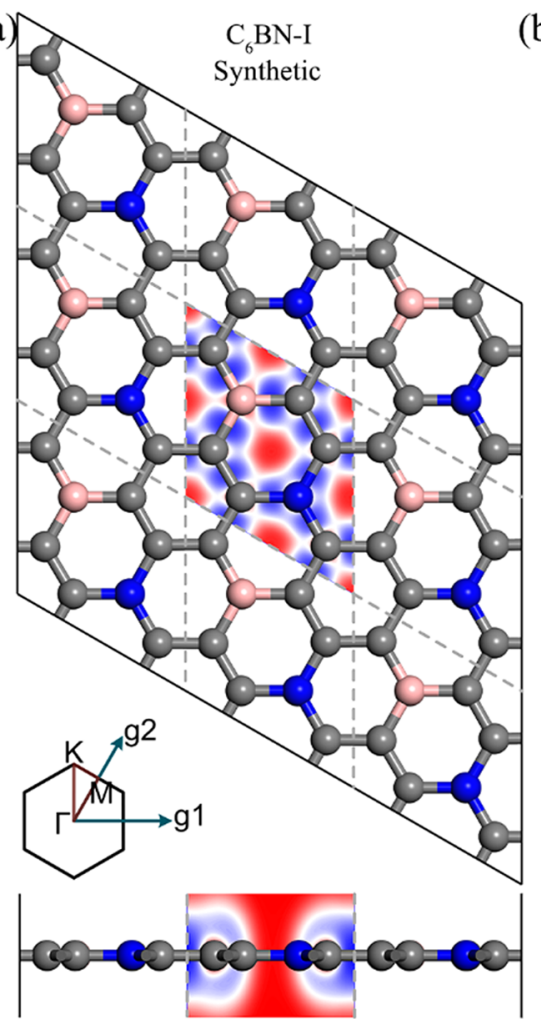

(d) 50
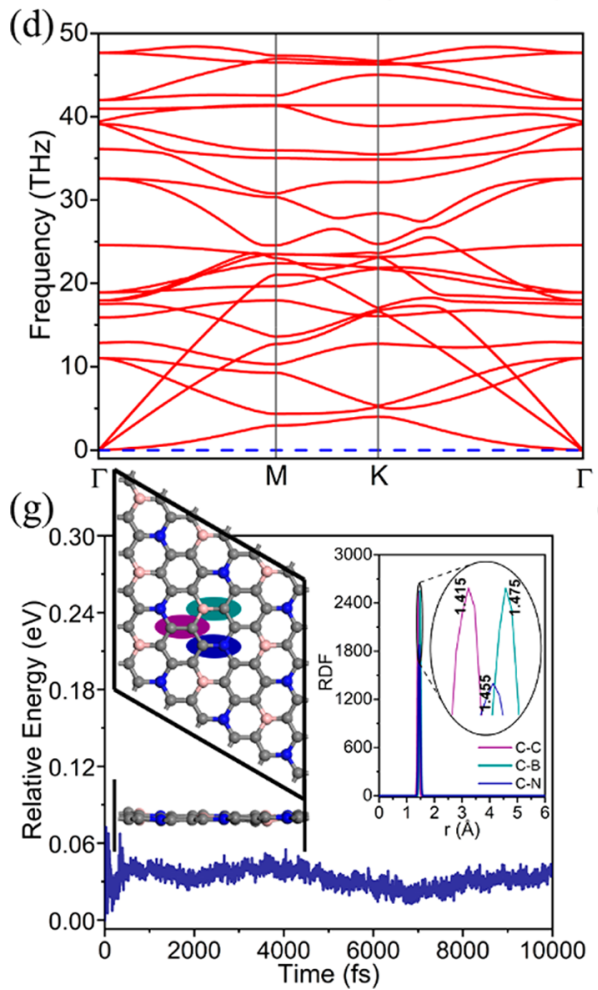

(b)

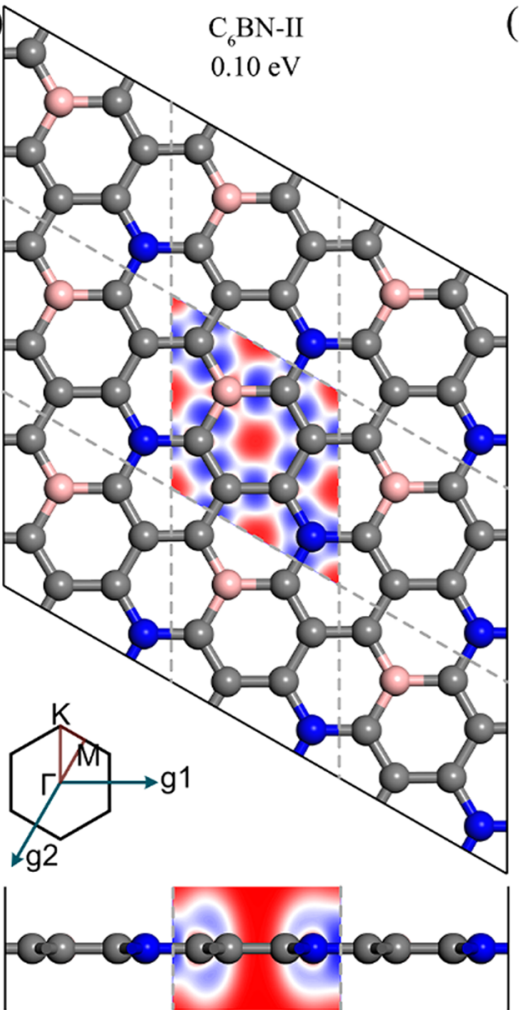

(e) 50

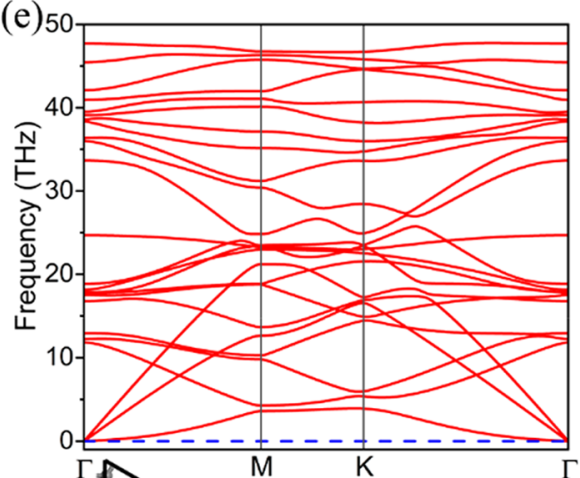

(h)

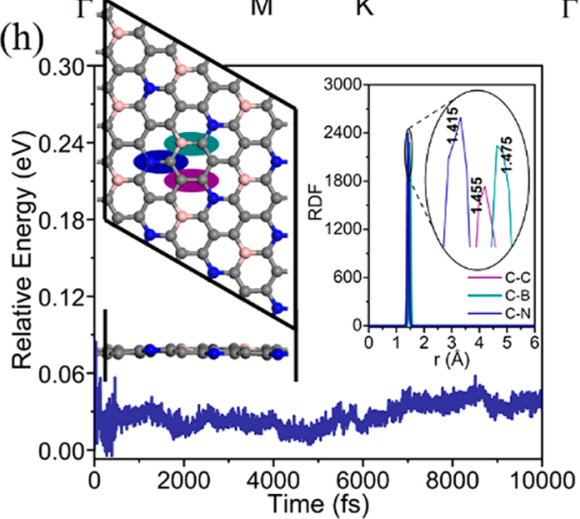

(c)
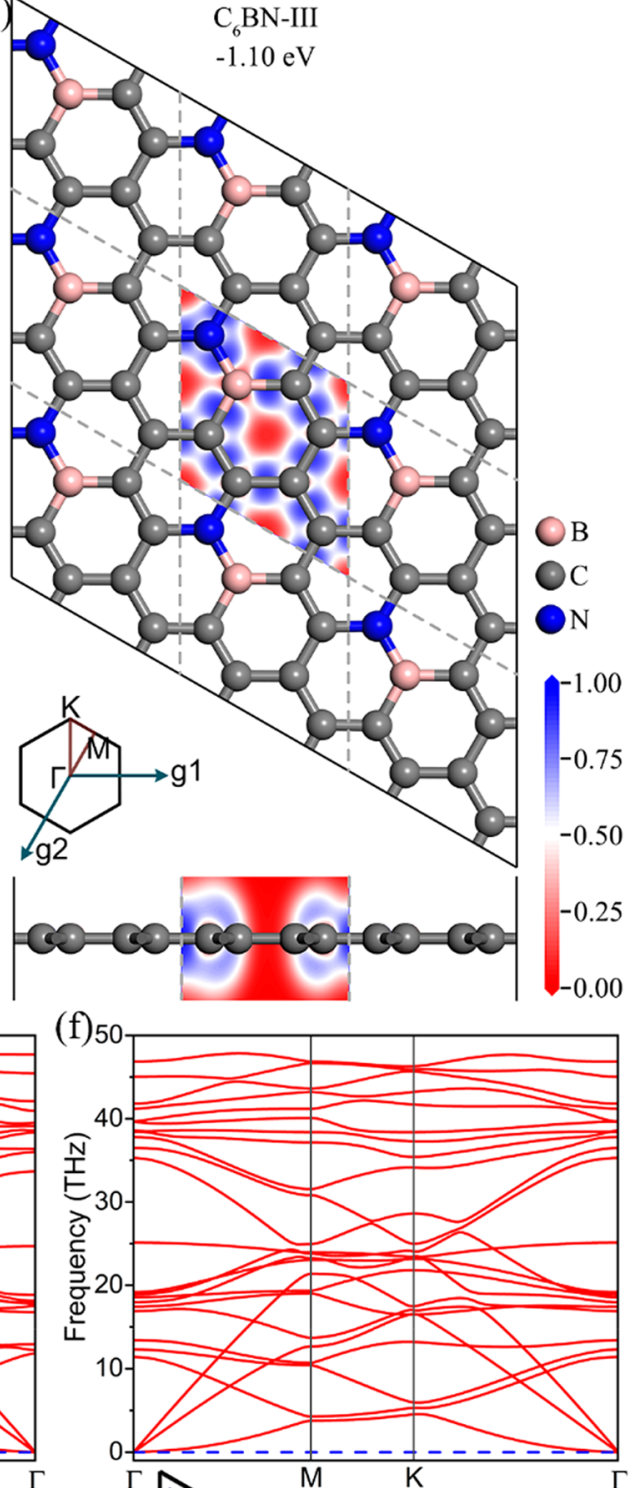

(i)

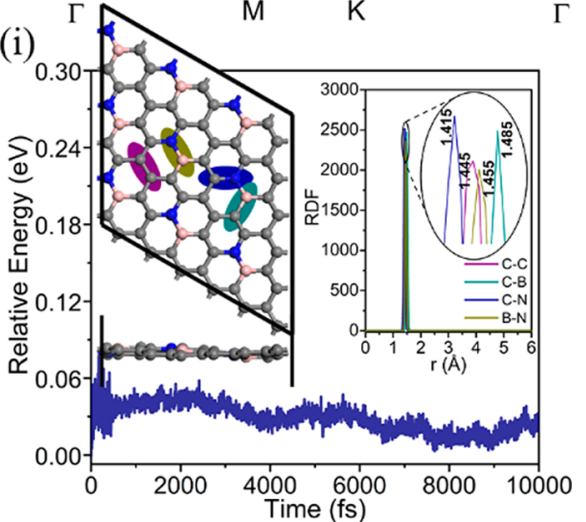

Figure 1. $\mathrm{C}_{6} \mathrm{BN}$ monolayers: $(\mathrm{a}-\mathrm{c})$ Top and side views of the optimized structure with Brillouin zone and electron localization function. $(\mathrm{d}-\mathrm{f})$ Phonon dispersion relation. $(\mathrm{g}-\mathrm{i})$ Total potential energy during the ab initio molecular dynamics simulation with final structure and radial distribution functions.

possibility of low-cost fabrication motivates us to explore $\mathrm{C}_{6} \mathrm{BN}$ monolayers as anode materials for $\mathrm{K}$-ion batteries.

We determine the basic properties and electrochemical performance of the synthesized $\mathrm{C}_{6} \mathrm{BN}$ monolayer and put forward two other $\mathrm{C}_{6} \mathrm{BN}$ monolayers based on first-principles calculations. For each of the three $\mathrm{C}_{6} \mathrm{BN}$ monolayers we first optimize the structure and examine the stability. Then, the band structure, density of states, Young's modulus, Poisson's ratio, and out-of-plane bending stiffness are studied to obtain insights into the electronic structure, in-plane strength, and flexibility. We also evaluate the adsorption and diffusion of $\mathrm{K}$ on the $\mathrm{C}_{6} \mathrm{BN}$ monolayers. The specific capacity and open 
Table 1. Structural Details, Relative Energy, and Material Properties

Young's
modulus
$(\mathrm{N} / \mathrm{m})$

(a) 8

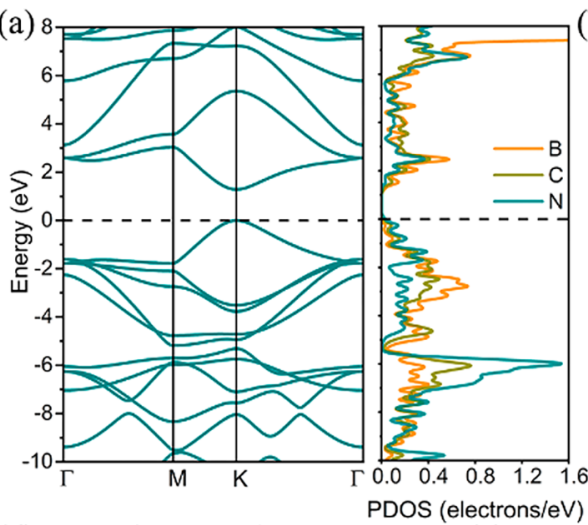

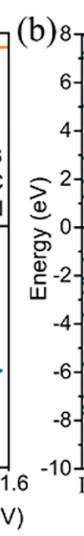
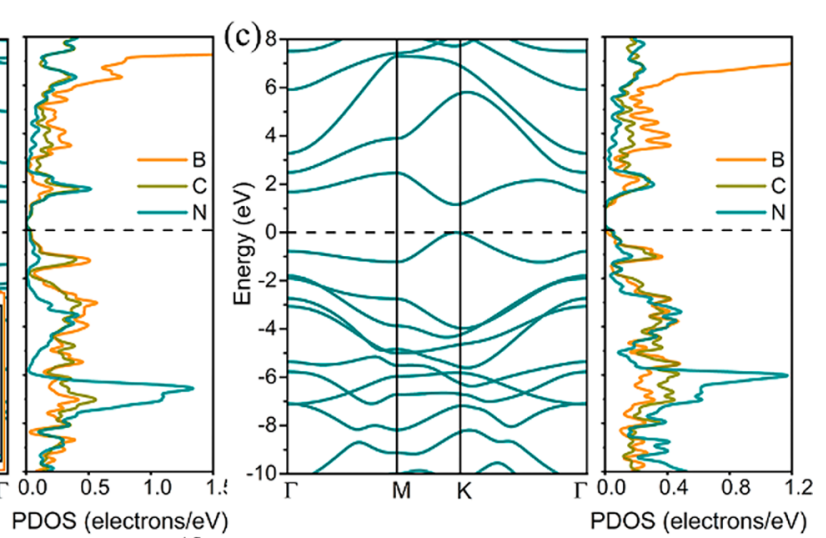

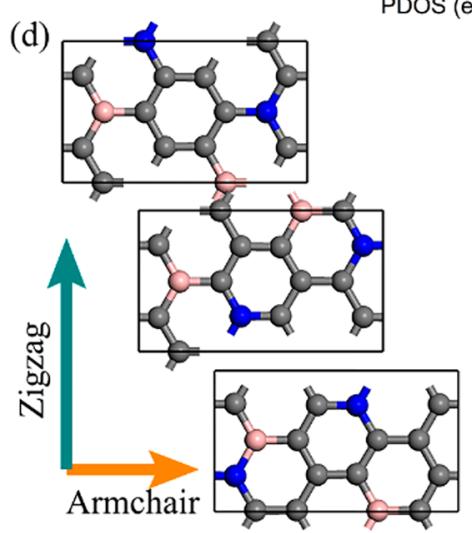

(g)

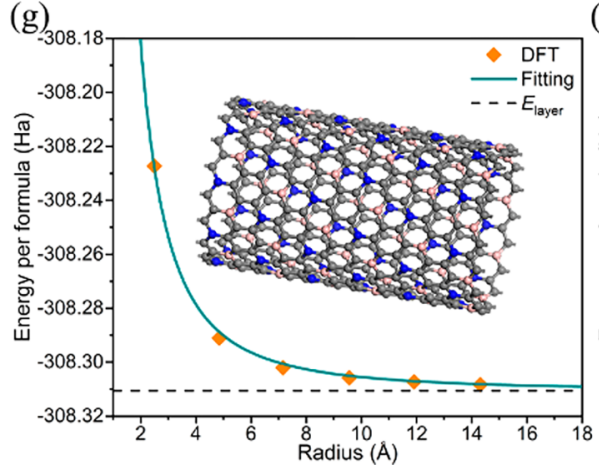

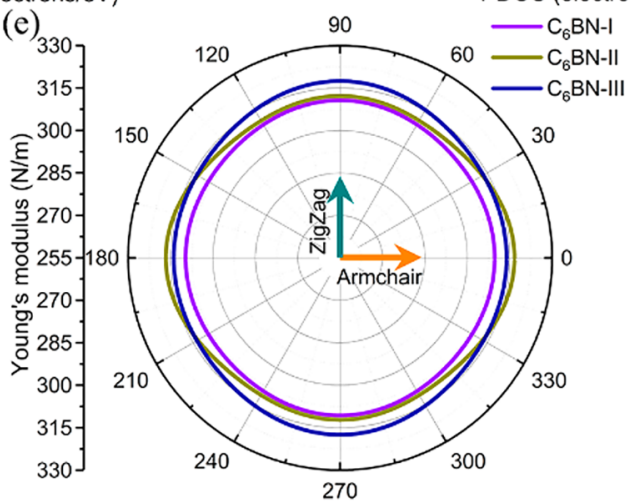

(h)

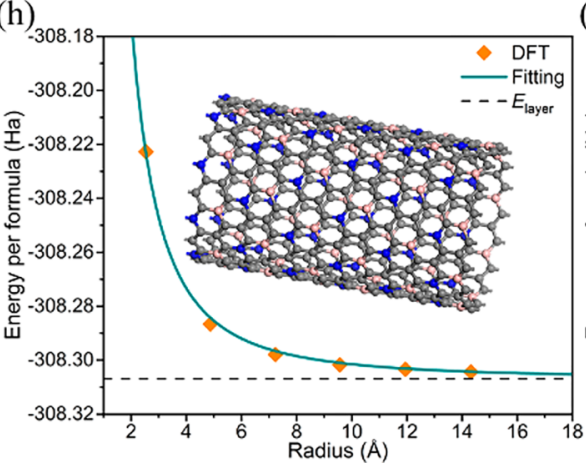

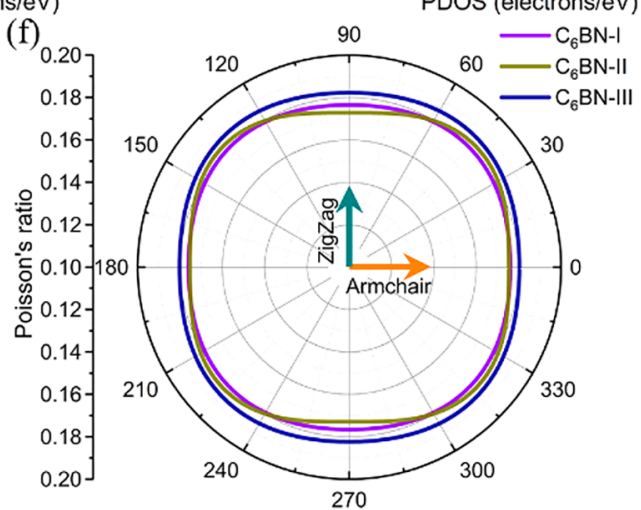

(i)

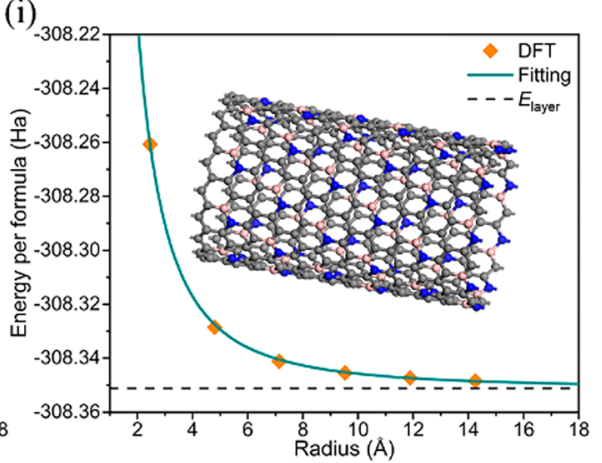

Figure 2. $\mathrm{C}_{6} \mathrm{BN}$ monolayers: $(\mathrm{a}-\mathrm{c})$ Band structure and partial densities of states. (d) Armchair and zigzag directions. (e, f) Young's modulus and Poisson's ratio. $(\mathrm{g}-\mathrm{i})$ Energy per formula unit for $\mathrm{C}_{6} \mathrm{BN}-\mathrm{I}, \mathrm{C}_{6} \mathrm{BN}-\mathrm{II}$, and $\mathrm{C}_{6} \mathrm{BN}-\mathrm{III}$ nanotubes of different radius with insets showing the typical structure.

circuit voltage (OCV) are calculated by obtaining the energetically favorable structures of potassiated $\mathrm{C}_{6} \mathrm{BN}$ monolayers. Finally, the effect of $\mathrm{K}$ adsorption in the conductivity of the $\mathrm{C}_{6} \mathrm{BN}$ monolayers is investigated.

\section{COMPUTATIONAL DETAILS}

First-principles calculations are performed by the $\mathrm{DMol} 3^{24,25}$ program using a double-numerical polarized basis, the all electron relativistic method, and the Perdew-Burke-Ernzerhof generalized gradient approximation of the exchange-correlation functional. The Grimme dispersion correction is adopted to describe the long-range van der Waals interaction. ${ }^{26}$ The convergence thresholds of the energy, maximum force, and displacement in the structure optimization are set to $1.0 \times 10^{-6} \mathrm{Ha}, 0.001 \mathrm{Ha} / \AA$, and $0.002 \AA$, respectively. Convergence tests (Figure S1) show that a Monkhorst-Pack $7 \times 7 \times$ $1 \mathrm{k}$-mesh for sampling the Brillouin zone provides reliable results. A small smearing of $5 \times 10^{-4} \mathrm{Ha}$ and a large global orbital cutoff of 5.6 
$\AA$ are employed in all calculations. To avoid artificial interaction between periodic images in the out-of-plane direction, a large vacuum thickness of $25 \AA$ is used. To evaluate the thermal stability of the $\mathrm{C}_{6} \mathrm{BN}$ monolayers, we use ab initio molecular dynamics simulations at 300 and $1200 \mathrm{~K}$ (NVT ensemble) for 10 ps with a time step of $1 \mathrm{fs}$. Still adopting the Perdew-Burke-Ernzerhof and Grimme schemes, the dynamic stability is investigated by calculating the phonon spectrum by the Phonopy ${ }^{27}$ and VASP ${ }^{28}$ (projector augmented-wave potentials, $1 \times 10^{-6} \mathrm{eV}$ energy convergence threshold, MonkhorstPack $12 \times 12 \times 1 \mathrm{k}$-mesh) programs, and charge densities and electron localization functions are obtained by means of the CASTEP $^{29}$ program (norm-conserving pseudopotentials, $5 \times 10^{-7}$ $\mathrm{eV} /$ atom energy convergence threshold, Monkhorst-Pack $7 \times 7 \times 1$ k-mesh).

\section{RESULTS AND DISCUSSION}

Structure, Stability, and Material Properties. The synthesized $\mathrm{C}_{6} \mathrm{BN}$ monolayer has a hexagonal unit cell with space group $P \overline{6} \mathrm{~m} 2$ and point group $D_{3 h}$, containing pure and $\mathrm{B}-\mathrm{N}$ para-doped $\mathrm{C}$ rings, as shown in Figure 1a. We obtain a lattice constant of $4.982 \AA$ and equilibrium $\mathrm{C}-\mathrm{C}, \mathrm{C}-\mathrm{B}$, and $\mathrm{C}-\mathrm{N}$ bond lengths of $1.412,1.473$, and $1.456 \AA$, respectively, in agreement with previously reported results. ${ }^{21}$ Because of the bond energy order $\mathrm{B}-\mathrm{N}(4.00 \mathrm{eV})>\mathrm{C}-\mathrm{C}(3.71 \mathrm{eV})>\mathrm{N}-\mathrm{C}$ $(2.83 \mathrm{eV})>\mathrm{B}-\mathrm{C}(2.59 \mathrm{eV})>\mathrm{B}-\mathrm{B}(2.32 \mathrm{eV})>\mathrm{N}-\mathrm{N}(2.11$ $\mathrm{eV}$ ) in borocarbonitrides, ${ }^{30} \mathrm{~B}-\mathrm{N}$ bonds are most favorable. However, as shown in Figure 1a, there exists no $\mathrm{B}-\mathrm{N}$ bond in the synthesized $\mathrm{C}_{6} \mathrm{BN}$ monolayer (named $\mathrm{C}_{6} \mathrm{BN}-\mathrm{I}$ in the following), probably because the synthesis is based on pyrolysis of specific precursors. By adjusting the sites of the $\mathrm{B}$ and $\mathrm{N}$ atoms in the hexagonal $\mathrm{C}$ network, we obtain two new monolayers, named $\mathrm{C}_{6} \mathrm{BN}-\mathrm{II}$ and $\mathrm{C}_{6} \mathrm{BN}-\mathrm{III}$. Unlike $\mathrm{C}_{6} \mathrm{BN}-\mathrm{I}$, the unit and primitive cells of $\mathrm{C}_{6} \mathrm{BN}-\mathrm{II}$ and $\mathrm{C}_{6} \mathrm{BN}-\mathrm{III}$ are different because of reduced symmetry, the unit cell being orthogonal (Figure S2), and the primitive cell being almost hexagonal (angle very close to $120^{\circ}$; Figure $1 \mathrm{~b}, \mathrm{c}$ ). To enable better comparison with $\mathrm{C}_{6} \mathrm{BN}-\mathrm{I}$, we used the primitive cells in further study. As shown in Figure $1 \mathrm{~b}, \mathrm{c}, \mathrm{C}_{6} \mathrm{BN}-\mathrm{II}(\mathrm{B}-\mathrm{N}$ metadoped) and $\mathrm{C}_{6} \mathrm{BN}-\mathrm{III}$ ( $\mathrm{B}-\mathrm{N}$ ortho-doped) stay perfectly planar. According to Table 1, the lattice constants and bond lengths of the $\mathrm{C}_{6} \mathrm{BN}$ monolayers are similar due to the identical elemental compositions and similarity of the crystal structures. Expectedly, introduction of strong B-N bonds in $\mathrm{C}_{6} \mathrm{BN}$-III lowers the total energy by $1.10 \mathrm{eV}$ per formula unit with respect to synthesized $\mathrm{C}_{6} \mathrm{BN}-\mathrm{I}$. The total energy of $\mathrm{C}_{6} \mathrm{BN}$ II turns out to be only $0.10 \mathrm{eV}$ higher than that of synthesized $\mathrm{C}_{6} \mathrm{BN}-\mathrm{I}$. Therefore, synthesis of $\mathrm{C}_{6} \mathrm{BN}-\mathrm{II}$ and $\mathrm{C}_{6} \mathrm{BN}$-III should be possible by the same method employed successfully in the case of $\mathrm{C}_{6} \mathrm{BN}-\mathrm{I}$. The insets in Figure $1 \mathrm{a}-\mathrm{c}$ show the electron localization function for the $\mathrm{C}_{6} \mathrm{BN}$ monolayers to analyze the electron distribution and bonding features. Because of the comparable electronegativities of $\mathrm{B}, \mathrm{C}$, and $\mathrm{N}$, high values (blue) between atoms indicate a covalent bond character as in the case of graphene. ${ }^{31}$

To examine the dynamical stability of the $\mathrm{C}_{6} \mathrm{BN}$ monolayers, we study the phonon spectra. The absence of imaginary frequencies in the entire first Brillouin zone demonstrates dynamical stability, as shown in Figure 1d-f. The maximal frequencies of 1616,1599 , and $1591 \mathrm{~cm}^{-1}$ obtained for $\mathrm{C}_{6} \mathrm{BN}$ I, $\mathrm{C}_{6} \mathrm{BN}-\mathrm{II}$, and $\mathrm{C}_{6} \mathrm{BN}-\mathrm{III}$, respectively, are comparable to those of $\mathrm{C}_{3} \mathrm{~N}\left(1638 \mathrm{~cm}^{-1}\right)$ and $\mathrm{C}_{3} \mathrm{~B}\left(1510 \mathrm{~cm}^{-1}\right)^{32}$ and indicate strong bonding. $\mathrm{Ab}$ initio molecular dynamics simulations are executed for each $\mathrm{C}_{6} \mathrm{BN}$ monolayer using a 3 $\times 3$ supercell. As shown in Figure $1 \mathrm{~g}-\mathrm{i}$, the fluctuations of the total energy are of the order of $0.01 \mathrm{eV}$ at $300 \mathrm{~K}$. The $\mathrm{C}_{6} \mathrm{BN}$ monolayers maintain their structure without relevant distortions, which is confirmed by peaks in the radial distribution functions at the equilibrium lengths of the $\mathrm{C}-\mathrm{B}, \mathrm{C}-\mathrm{C}$, and $\mathrm{C}-$ $\mathrm{N}$ bonds (insets of Figure $1 \mathrm{~g}-\mathrm{i}$ ). Similar results are observed up to $1200 \mathrm{~K}$ (Figure S3), indicating excellent thermal stability to endure elevated temperatures during device operation. The mechanical stability of the $\mathrm{C}_{6} \mathrm{BN}$ monolayers is examined by determining the linear elastic constants, $C_{\mathrm{ij}}$, by fitting the energy of the orthogonal unit cell under armchair axial $\left(\begin{array}{ll}\varepsilon & 0 \\ 0 & 0\end{array}\right)$, hydrostatic planar $\left(\begin{array}{ll}\varepsilon & 0 \\ 0 & \varepsilon\end{array}\right)$, zigzag axial $\left(\begin{array}{ll}0 & 0 \\ 0 & \varepsilon\end{array}\right)$, and shear $\left(\begin{array}{ll}0 & \varepsilon \\ \varepsilon & 0\end{array}\right)$ deformations for external strain $\varepsilon$ from $-2 \%$ to $2 \%$ (steps of $0.5 \%$ ). We obtain for $C_{11}, C_{12}, C_{22}$, and $C_{44}$ values of $320,56,321$, and $131 \mathrm{~N} / \mathrm{m}$ for $\mathrm{C}_{6} \mathrm{BN}-\mathrm{I} ; 327,56,322$, and 132 $\mathrm{N} / \mathrm{m}$ for $\mathrm{C}_{6} \mathrm{BN}-\mathrm{II}$; and $325,59,328$, and $132 \mathrm{~N} / \mathrm{m}$ for $\mathrm{C}_{6} \mathrm{BN}$ III; i.e., in each case the Born criteria $\left(C_{11}>0, C_{22}>0, C_{11} C_{22}\right.$ $\left.-C_{12}^{2}>0, C_{44}>0\right)^{33}$ imply mechanical stability.

Having confirmed the structural stability of the $\mathrm{C}_{6} \mathrm{BN}$ monolayers, the band structure and partial densities of states are addressed in Figure $2 \mathrm{a}-\mathrm{c}$ to examine the electronic properties. $\mathrm{C}_{6} \mathrm{BN}-\mathrm{I}$ and $\mathrm{C}_{6} \mathrm{BN}-\mathrm{III}$ show similar band structures with both the valence band maximum and conduction band minimum at the $\mathrm{K}$ point (band gaps of 1.28 and $1.16 \mathrm{eV}$, respectively). The partial densities of states indicate that the valence band edge is mainly due to the $\mathrm{C}$ and $\mathrm{N}$ atoms, whereas the conduction band edge is mainly due to the $\mathrm{B}$ and $\mathrm{C}$ atoms. $\mathrm{C}_{6} \mathrm{BN}-\mathrm{II}$ is characterized by a very small direct band gap of only $0.13 \mathrm{eV}$ at the $\mathrm{K}$ point with the bands resembling a Dirac cone, pointing to excellent charge transport.

As the mechanical properties are correlated with the battery cyclability, we estimate the in-plane stiffness by deriving the direction-dependent $(\theta$, angle to the armchair direction) Young's modulus

$$
E(\theta)=\frac{C_{11} C_{22}-C_{12}{ }^{2}}{C_{11} \sin ^{4} \theta+C_{22} \cos ^{4} \theta+\left(\frac{C_{11} C_{22}-C_{12}{ }^{2}}{C_{44}}-2 C_{12}\right) \cos ^{2} \theta \sin ^{2} \theta}
$$

and Poisson's ratio

$$
\nu(\theta)=-\frac{\left(C_{11}+C_{22}-\frac{C_{11} C_{22}-C_{12}^{2}}{C_{44}}\right) \cos ^{2} \theta \sin ^{2} \theta-C_{12}\left(\sin ^{4} \theta+\cos ^{4} \theta\right)}{C_{11} \sin ^{4} \theta+C_{22} \cos ^{4} \theta+\left(\frac{C_{11} C_{22}-C_{12}{ }^{2}}{C_{44}}-2 C_{12}\right) \cos ^{2} \theta \sin ^{2} \theta}
$$

from the linear elastic constants. ${ }^{34}$ The polar diagrams of $E(\theta)$ and $\nu(\theta)$ in Figure 2e,f show that Young's modulus and Poisson's ratio are almost isotropic in each case. Unlike the electronic properties, the mechanical properties of the $\mathrm{C}_{6} \mathrm{BN}$ monolayers are very similar. The average Young's modulus and Poisson's ratio are $309 \mathrm{~N} / \mathrm{m}$ and 0.178 for $\mathrm{C}_{6} \mathrm{BN}-\mathrm{I}, 313 \mathrm{~N} / \mathrm{m}$ and 0.178 for $\mathrm{C}_{6} \mathrm{BN}-\mathrm{II}$, and $315 \mathrm{~N} / \mathrm{m}$ and 0.183 for $\mathrm{C}_{6} \mathrm{BN}-\mathrm{II}$, which is comparable to graphene $(342 \mathrm{~N} / \mathrm{m}$ and 0.173$)$ and reflects strong bonding and high in-plane stiffness.

To evaluate the usability of $\mathrm{C}_{6} \mathrm{BN}$-based anodes in wearable electronics, we calculate the out-of-plane bending strength $\left(B_{\mathrm{M}}\right)$ by fitting to the formula ${ }^{35}$

$$
E_{\text {tube }}=E_{\text {layer }}-\frac{1}{2 r^{2}} S_{\text {layer }} B_{M}
$$



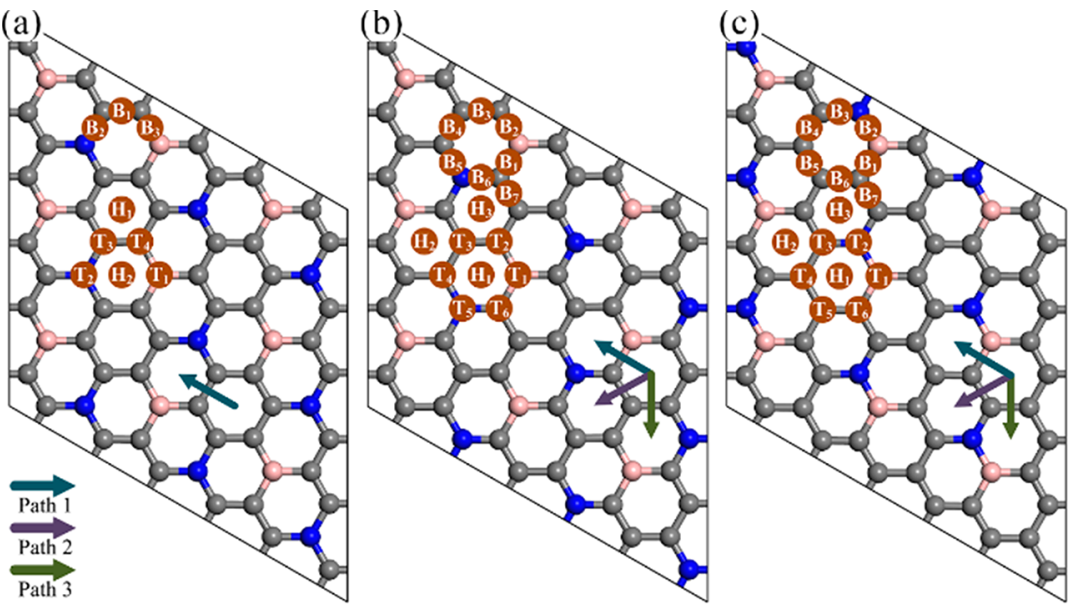

Figure 3. $\mathrm{K}$ adsorption sites and diffusion paths for (a) $\mathrm{C}_{6} \mathrm{BN}-\mathrm{I}$, (b) $\mathrm{C}_{6} \mathrm{BN}-\mathrm{II}$, and (c) $\mathrm{C}_{6} \mathrm{BN}-\mathrm{III}$.

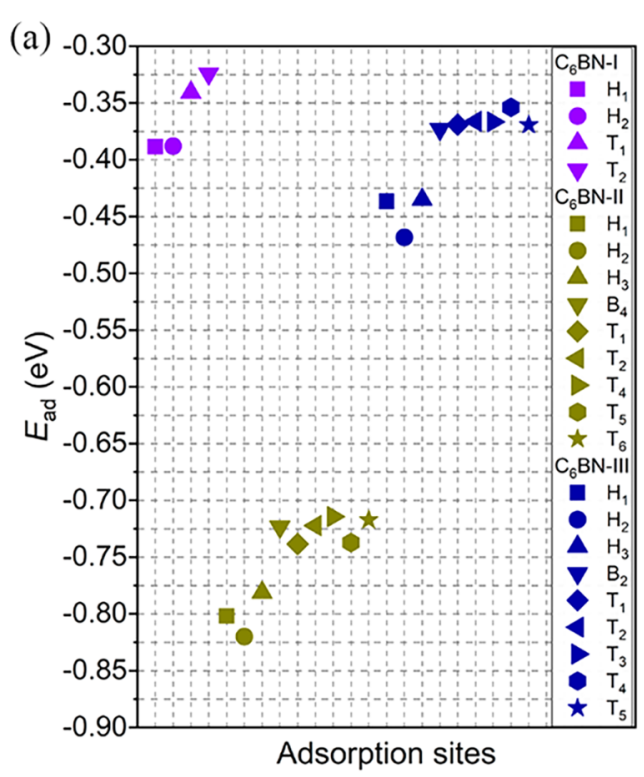

(b)

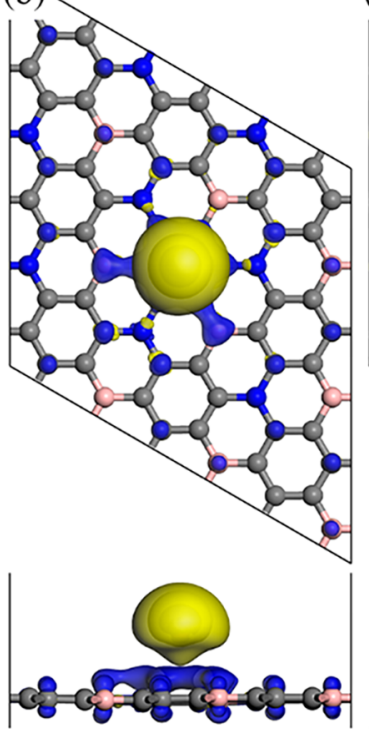

$(\mathrm{f})_{0.20}$

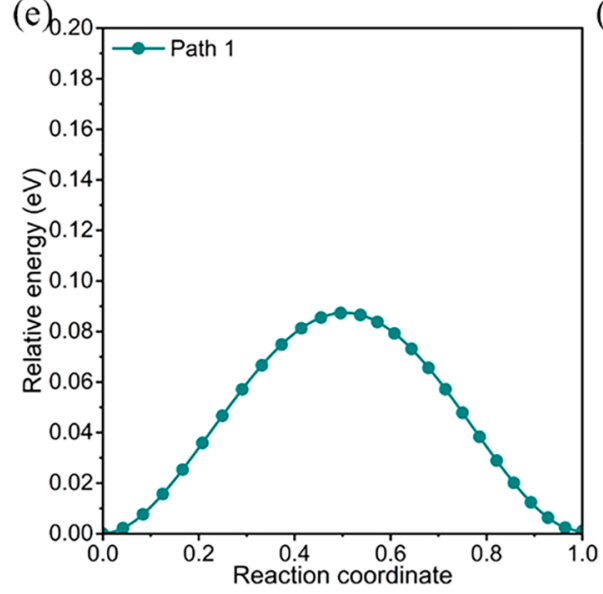

(c)

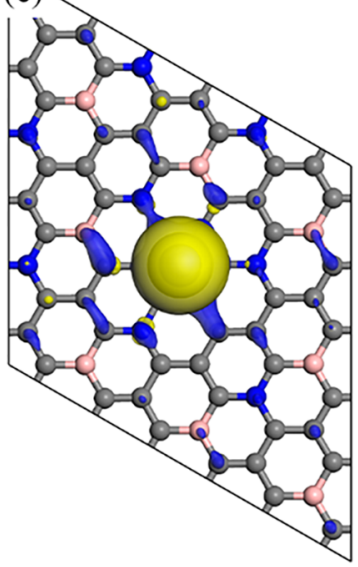

(d) $\pm 9.5 \times 10^{-3} \mathrm{e} / \AA^{3}$
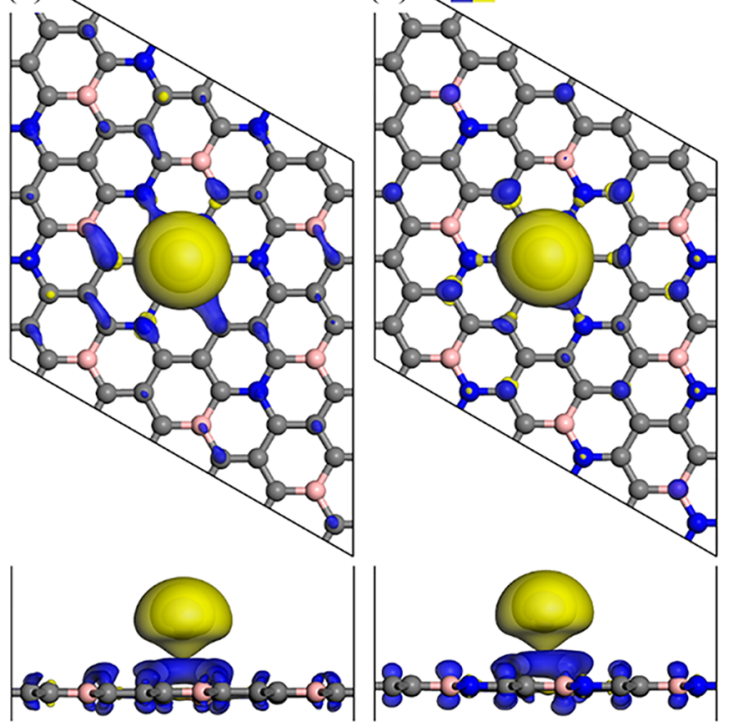

$(\mathrm{g})_{0.20} \longrightarrow$ - Path 1
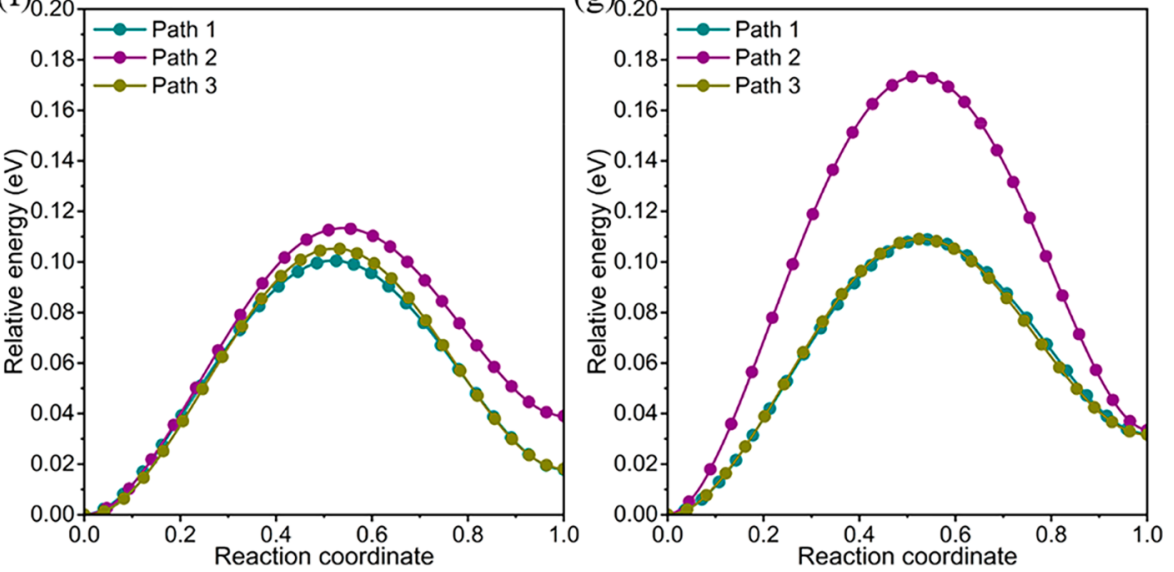

Figure 4. $\mathrm{C}_{6} \mathrm{BN}$ monolayers: (a) Adsorption energy of a $\mathrm{K}$ atom. (b-d) Charge density difference due to adsorption of a $\mathrm{K}$ atom at the energetically favorable site. (e, f) Energy profiles for $\mathrm{K}$ diffusion.

where $E_{\text {tube }}$ and $E_{\text {layer }}$ are the total energies per formula unit of a $\mathrm{C}_{6} \mathrm{BN}$ nanotube and a corresponding $\mathrm{C}_{6} \mathrm{BN}$ monolayer, respectively, $S_{\text {layer }}$ is the area per formula unit of the $\mathrm{C}_{6} \mathrm{BN}$ monolayer, and $r$ is the radius of the $\mathrm{C}_{6} \mathrm{BN}$ nanotube. For each of the $\mathrm{C}_{6} \mathrm{BN}$ monolayers, nanotubes with six different radii are constructed. The fitting curves are shown in Figure $2 \mathrm{~g}-\mathrm{i}$ and the structural details of the optimized nanotubes are summarized in Table $S 1$. We obtain $B_{\mathrm{M}}$ values of 1.30, 1.36, and $1.38 \mathrm{eV}$ for $\mathrm{C}_{6} \mathrm{BN}-\mathrm{I}, \mathrm{C}_{6} \mathrm{BN}-\mathrm{II}$, and $\mathrm{C}_{6} \mathrm{BN}-\mathrm{III}$, respectively, which are lower than those reported for the well-known flexible 
(a)

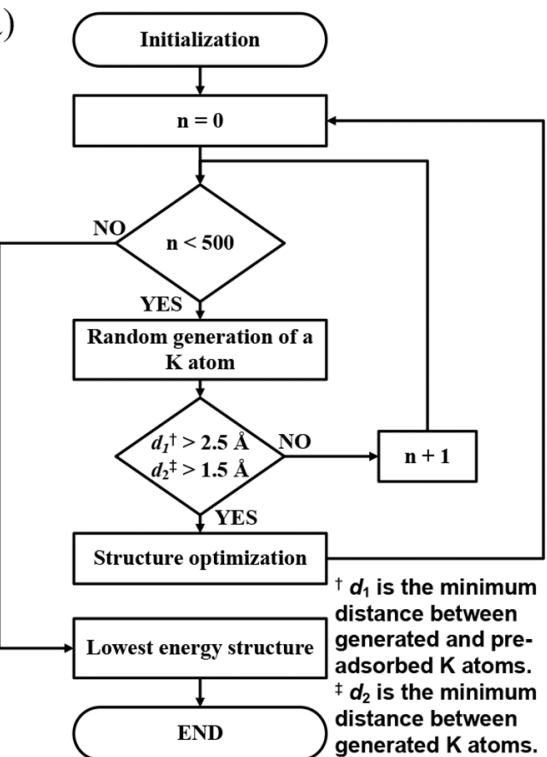

(e)
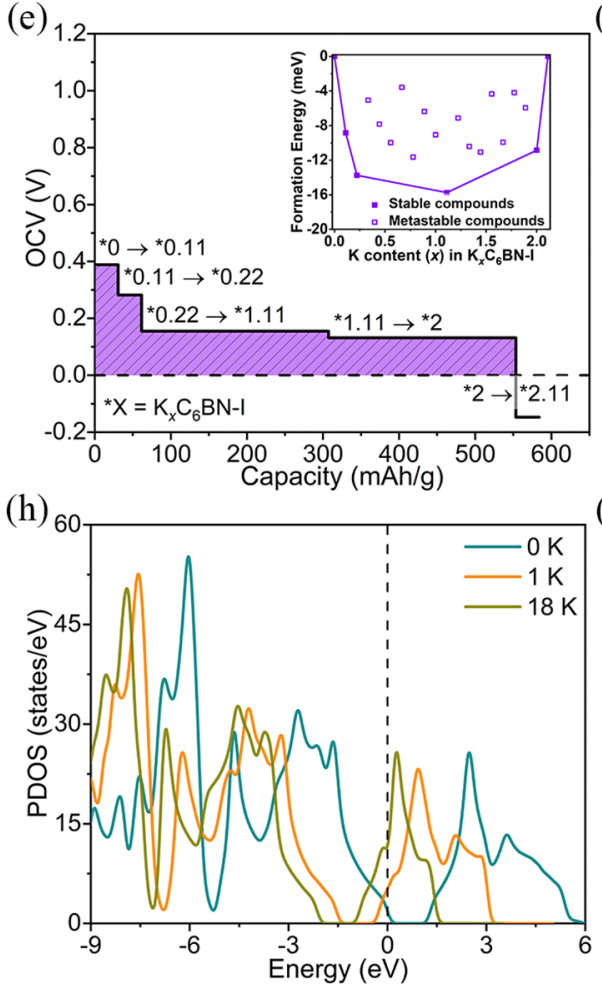

(b)

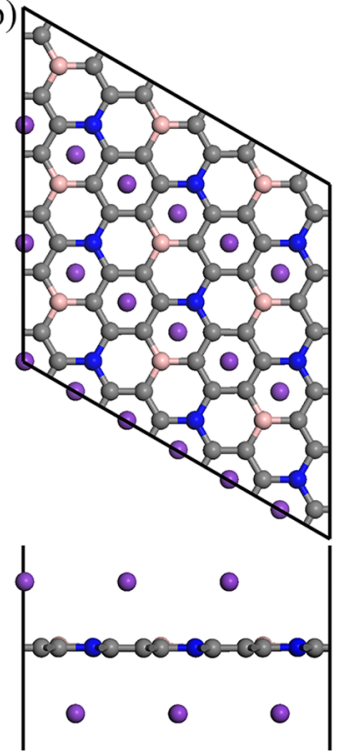

(f)

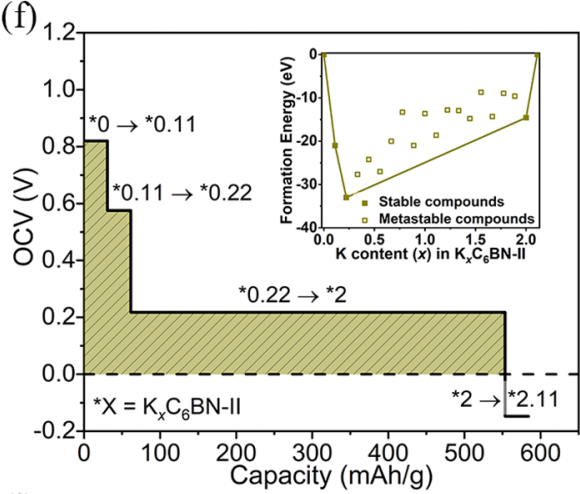

(c)

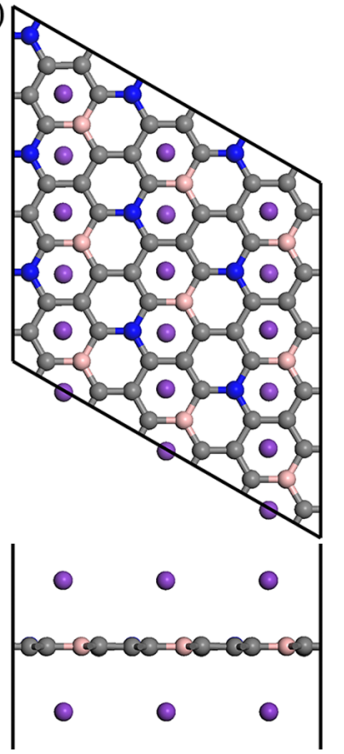

(d)

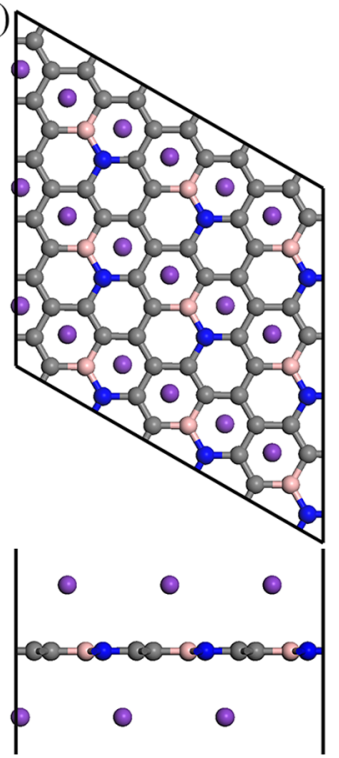

$(\mathrm{g})$

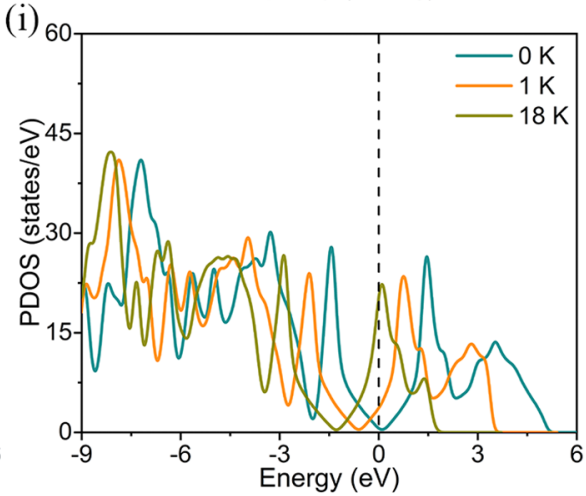

Figure 5. $\mathrm{K}_{x} \mathrm{C}_{6} \mathrm{BN}$ monolayers: (a) Flowchart of the script used to obtain the lowest energy structure when adding a $\mathrm{K}$ atom. No additional sites are found when the number of attempts $n$ approaches 500 . (b-d) Maximally potassiated $\mathrm{C}_{6} \mathrm{BN}$ monolayer. (e-g) OCV as a function of the specific capacity with insets showing the formation energy as a function of $x$. ( $\mathrm{h}-\mathrm{j})$ Variation of the density of states during $\mathrm{K}$ adsorption.

2D materials graphene $\left(1.44 \mathrm{eV}^{35}\right)$ and $\mathrm{MoS}_{2}\left(9.33 \mathrm{eV}^{36}\right)$. This indicates enhanced flexibility of the $\mathrm{C}_{6} \mathrm{BN}$ monolayers and, therefore, great potential in wearable electronics.

Adsorption and Diffusion of $\mathrm{K}$. Although the $\mathrm{C}_{6} \mathrm{BN}$ monolayers are promising anode materials in terms of their low mass density, high stability, and excellent mechanical properties, spontaneous adsorption of metal atoms is an essential prerequisite. For this reason, we determine the energetically favorable adsorption site of $\mathrm{K}$, i.e., the most likely position of a $\mathrm{K}$ atom on the anode material. Based on the different symmetries, nine possible adsorption sites are considered for $\mathrm{C}_{6} \mathrm{BN}-\mathrm{I}$ and 16 for $\mathrm{C}_{6} \mathrm{BN}-\mathrm{II}$ and $\mathrm{C}_{6} \mathrm{BN}-\mathrm{III}$ as shown in Figure 3
$\left(\mathrm{T}_{n}\right.$, site on top of an atom; $\mathrm{B}_{n}$, site on top of a bond; $\mathrm{H}_{n}$, site on top of the center of a $\mathrm{C}$ ring). Unstable adsorption sites show up in the structure optimization by spontaneous diffusion of the $\mathrm{K}$ atom to another adsorption site. To determine the affinity of $\mathrm{K}$ to a $\mathrm{C}_{6} \mathrm{BN}$ monolayer, we calculate the adsorption energy $E_{\mathrm{ad}}=E_{\mathrm{KC}_{6} \mathrm{BN}}-E_{\mathrm{C}_{6} \mathrm{BN}}-\mu_{\mathrm{K}}$, where $E_{\mathrm{KC}_{6} \mathrm{BN}}$ and $E_{\mathrm{C}_{6} \mathrm{BN}}$ are the total energies of a $\mathrm{C}_{6} \mathrm{BN}$ monolayer after and before $\mathrm{K}$ adsorption, respectively, and $\mu_{\mathrm{K}}$ is the chemical potential of a $\mathrm{K}$ atom from the bcc bulk. The obtained values are summarized in Figure 4a. The negative values indicate spontaneous adsorption of $\mathrm{K}$. It turns out that the $\mathrm{H}_{n}$ sites are more attractive to $\mathrm{K}$ than the $\mathrm{T}_{n}$ and $\mathrm{B}_{n}$ sites, which can be attributed 
to interaction with delocalized electrons of the $\mathrm{C}$ rings, see the results of the electron localization function in Figure $1 \mathrm{a}-\mathrm{c}$. Concretely, the favorable adsorption sites are $\mathrm{H}_{1}$ for $\mathrm{C}_{6} \mathrm{BN}-\mathrm{I}$ and $\mathrm{H}_{2}$ for both $\mathrm{C}_{6} \mathrm{BN}$-II and $\mathrm{C}_{6} \mathrm{BN}$-III with adsorption energies of $-0.39,-0.82$, and $-0.47 \mathrm{eV}$ and adsorption heights of $2.61,2.59$, and $2.60 \AA$, respectively.

To gain further insights into the interaction between $\mathrm{K}$ and a $\mathrm{C}_{6} \mathrm{BN}$ monolayer, we calculate for the energetically favorable adsorption site the electron density difference $\rho=\rho_{\mathrm{KC} 6 \mathrm{BN}}-$ $\rho_{\mathrm{C} 6 \mathrm{BN}}-\rho_{\mathrm{K}}$, where $\rho_{\mathrm{KC} 6 \mathrm{BN}}$ and $\rho_{\mathrm{C} 6 \mathrm{BN}}$ are the electron densities of a $\mathrm{C}_{6} \mathrm{BN}$ monolayer after and before $\mathrm{K}$ adsorption, respectively, and $\rho_{\mathrm{K}}$ is the electron density of an isolated $\mathrm{K}$ atom. The results are shown in Figure $4 \mathrm{~b}-\mathrm{d}$ with blue and yellow isosurfaces representing electron accumulation and depletion, respectively. We observe a pronounced transfer of electrons from the $\mathrm{K}$ atom to the $\mathrm{C}_{6} \mathrm{BN}$ monolayer, consistent with the much smaller electronegativity of $\mathrm{K}$ as compared to $\mathrm{B}$, $\mathrm{C}$, and $\mathrm{N}$. Using the Hirshfeld partitioning method, we derive transfers of $0.69,0.68$, and 0.69 electrons to $\mathrm{C}_{6} \mathrm{BN}-\mathrm{I}, \mathrm{C}_{6} \mathrm{BN}-\mathrm{II}$, and $\mathrm{C}_{6} \mathrm{BN}-\mathrm{III}$, respectively. Despite the strong interaction, the adsorption of $\mathrm{K}$ has virtually no effect on the structure of the $\mathrm{C}_{6} \mathrm{BN}$ monolayers (no corrugations or other deformations).

Because the diffusion barrier $\left(E_{\mathrm{bar}}\right)$ determines the battery charge/discharge rate, we next study the migration of $\mathrm{K}$ on the $\mathrm{C}_{6} \mathrm{BN}$ monolayers. As adsorption of $\mathrm{K}$ is strongly favorable at the $\mathrm{H}_{n}$ sites as compared to the $\mathrm{T}_{n}$ and $\mathrm{B}_{n}$ sites, we focus on diffusion from the energetically favorable adsorption site to the neighboring $\mathrm{H}_{n}$ site. There is only one such diffusion path for $\mathrm{C}_{6} \mathrm{BN}-\mathrm{I}$, whereas there are three possible paths for $\mathrm{C}_{6} \mathrm{BN}-\mathrm{II}$ and $\mathrm{C}_{6} \mathrm{BN}-\mathrm{III}$, as shown in Figure 3. Employing the linear and quadratic synchronous transit methods as well as the transition-state confirmation tool of DMol3, we obtain the diffusion energy profiles shown in Figure $4 \mathrm{e}-\mathrm{g}$. The saddle points of all the considered diffusion paths appear in the middle of a bond connecting two $\mathrm{C}$ rings. Because of the high symmetry of $\mathrm{C}_{6} \mathrm{BN}-\mathrm{I}$, the $\mathrm{K}$ diffusion in this case is isotropic with $E_{\mathrm{bar}}=0.087 \mathrm{eV}$. In the case of $\mathrm{C}_{6} \mathrm{BN}$-II, the diffusion barriers of the three paths are very similar $(0.100,0.113$, and $0.105 \mathrm{eV}$ ), resulting in almost isotropic diffusion. On the other hand, in the case of $\mathrm{C}_{6} \mathrm{BN}-\mathrm{III}$, the diffusion is anisotropic with $E_{\text {bar }}=0.173 \mathrm{eV}$ for path 2 and $E_{\text {bar }}=0.109 \mathrm{eV}$ for both paths 1 and 3. Using the Arrhenius equation, $D \propto \exp \left(-E_{\mathrm{bar}} / \mathrm{k}_{\mathrm{B}} T\right)$, where $D, \mathrm{k}_{\mathrm{B}}$, and $T$ are the diffusion coefficient, Boltzmann constant, and operating temperature, respectively, we estimate for $T=300 \mathrm{~K}$ that the diffusion is 12 times faster along paths 1 and 3 than along path 2 . The fact that $E_{\mathrm{bar}}$ is much smaller than for commercial Li-graphite batteries $(0.45-1.20 \mathrm{eV})^{37,38}$ indicates that $\mathrm{C}_{6} \mathrm{BN}$ monolayers can provide excellent rate performance.

Specific Capacity and OCV. The specific capacity and OCV are two key electrochemical parameters of an anode material. For this reason, we study the concentrationdependent adsorption behavior of $\mathrm{K}$ on the $\mathrm{C}_{6} \mathrm{BN}$ monolayers. To accurately simulate the potassiation process during charging, we add $\mathrm{K}$ atoms one after the other to a $3 \times 3$ supercell. The lowest energy structure is obtained for each $\mathrm{K}$ concentration ( 1 to $19 \mathrm{~K}$ atoms) and $\mathrm{C}_{6} \mathrm{BN}$ monolayer by the method presented in Figure 5a, considering a total of 3660 structures. The relative stabilities of the intermediate $\mathrm{K}_{x} \mathrm{C}_{6} \mathrm{BN}$ structures are then determined relative to the pristine $\left(\mathrm{C}_{6} \mathrm{BN}\right)$ and maximally potassiated $\left(\mathrm{K}_{2.11} \mathrm{C}_{6} \mathrm{BN}\right)$ monolayers in terms of the formation energy ${ }^{39}$

$$
E_{\mathrm{f}}=E_{\mathrm{K}_{x} \mathrm{C}_{6} \mathrm{BN}}-\frac{x E_{\mathrm{K}_{2.11} \mathrm{C}_{6} \mathrm{BN}}+(2.11-x) E_{\mathrm{C}_{6} \mathrm{BN}}}{2.11}
$$

based on total energy calculations. The obtained convex hulls are shown as insets in Figure $5 \mathrm{e}-\mathrm{g}$. We find for $\mathrm{K}$ adsorption on $\mathrm{C}_{6} \mathrm{BN}-\mathrm{I}$ four points $(x=0.11,0.22,1.11$, and 2$)$ on the convex hull, i.e., only these four intermediated $\mathrm{K}_{x} \mathrm{C}_{6} \mathrm{BN}$ structures are thermodynamically stable. For $\mathrm{C}_{6} \mathrm{BN}-\mathrm{II}$ and $\mathrm{C}_{6} \mathrm{BN}$-III there are only three thermodynamically stable intermediate $\mathrm{K}_{x} \mathrm{C}_{6} \mathrm{BN}$ structures (as $x=1.11$ here is metastable). The intermediate structures during potassiation are shown in Figure S4.

The voltage associated with the potassiation $\mathrm{K}_{x} \mathrm{C}_{6} \mathrm{BN}+(y-$ $x) \mathrm{K}^{+}+(y-x) e^{-} \rightarrow \mathrm{K}_{y} \mathrm{C}_{6} \mathrm{BN}$ is

$$
V=-\frac{E_{\mathrm{K}_{y} \mathrm{C}_{6} \mathrm{BN}}-E_{\mathrm{K}_{x} \mathrm{C}_{6} \mathrm{BN}}-(y-x) \mu_{\mathrm{K}}}{(y-x) e}
$$

which yields the OCV curves shown in Figure $5 \mathrm{e}-\mathrm{g}$. For increasing $\mathrm{K}$ concentration, the $\mathrm{OCV}$ decreases in each case monotonically from an initial positive value. Once a negative value is reached, the $\mathrm{K}$ adsorption must stop to prevent dendrite formation. The voltage profile of $\mathrm{C}_{6} \mathrm{BN}-\mathrm{I}$ in Figure 5e shows at the beginning a rapid drop to less than half of the initial value $(0.39 \mathrm{~V}$ at $x=0 ; 0.15 \mathrm{~V}$ at $x=0.22)$ and afterward a wide $\mathrm{K}$ concentration range with almost constant value $(0.13$ $\mathrm{V}$ at $x=2)$ in that the battery can provide stable output voltage during discharge. At the $\mathrm{K}_{2} \mathrm{C}_{6} \mathrm{BN}$ to $\mathrm{K}_{2.11} \mathrm{C}_{6} \mathrm{BN}$ transition the voltage switches from positive to negative, suggesting that the maximal $\mathrm{K}$ concentration is reached at $x=2$ (fully potassiated $\mathrm{K}_{2} \mathrm{C}_{6} \mathrm{BN}$ ). The potential profiles of $\mathrm{C}_{6} \mathrm{BN}-\mathrm{II}$ and $\mathrm{C}_{6} \mathrm{BN}-\mathrm{III}$ in Figure $5 f, g$ are very similar to that of $\mathrm{C}_{6} \mathrm{BN}$-I. Therefore, all $\mathrm{C}_{6} \mathrm{BN}$ monolayers can store $2 \mathrm{~K}$ atoms per $\mathrm{C}_{6} \mathrm{BN}$ formula unit, which is almost twice the storage capacity of a graphite anode ( $1 \mathrm{~K}$ atom per $8 \mathrm{C}$ atoms). ${ }^{15}$ We obtain average OCVs for the whole potassiation of $0.16,0.27$, and $0.20 \mathrm{~V}$ for $\mathrm{C}_{6} \mathrm{BN}-\mathrm{I}$, $\mathrm{C}_{6} \mathrm{BN}-\mathrm{II}$, and $\mathrm{C}_{6} \mathrm{BN}-\mathrm{III}$, respectively. These low values ensure that there is no risk of dendrite growth ( $\mathrm{K}$ is stored homogeneously on the $\mathrm{C}_{6} \mathrm{BN}$ monolayers, see Figure S5) and that the assembled battery can provide high voltage. ${ }^{40}$

After determining the maximal $\mathrm{K}$ concentration, the specific capacity of the half-cell is obtained as $C=n F / 3.6 M_{\mathrm{C} 6 \mathrm{BN}}$, where $n, F$, and $M_{\mathrm{C} 6 \mathrm{BN}}$ are the number of transferred electrons, Faraday constant, and mass of the $\mathrm{C}_{6} \mathrm{BN}$ monolayer, respectively. We find that fully potassiated $\mathrm{K}_{2} \mathrm{C}_{6} \mathrm{BN}$ provides a specific capacity of $553 \mathrm{mAh} / \mathrm{g}$, outperforming graphite (279 $\mathrm{mAh} / \mathrm{g}$ for $\left.\mathrm{KC}_{8}\right),{ }^{15} \mathrm{Ti}_{3} \mathrm{C}_{2}(192 \mathrm{mAh} / \mathrm{g}),{ }^{41} \mathrm{MoN}_{2}$ (432 mAh/ $\mathrm{g}){ }^{42}$ and phosphorene $\left(433 \mathrm{mAh} / \mathrm{g}\right.$ for $\left.\mathrm{K}_{0.5} \mathrm{P}\right) .^{43}$ The maximal in-plane expansion due to $\mathrm{K}$ adsorption is found to be less than $1 \%$ for all $\mathrm{C}_{6} \mathrm{BN}$ monolayers. Together with the absence of structural deformations (Figure $4 \mathrm{~b}-\mathrm{d}$ ), this points to robustness of anodes based on $\mathrm{C}_{6} \mathrm{BN}$ monolayers and, therefore, to excellent cyclability and long service life of the battery.

The conductivity of the anode material determines the Ohmic heating during battery operation. As mentioned previously, $\mathrm{K}$ adsorption comes along with electron transfer to the $\mathrm{C}_{6} \mathrm{BN}$ monolayers. For further evaluation of the consequences, we compare in Figure $5 \mathrm{~h}-\mathrm{j}$ the (partial) density of states of $\mathrm{a}_{6} \mathrm{BN}$ monolayer before $\mathrm{K}$ adsorption with those after adsorption of 1 and $18 \mathrm{~K}$ atoms. All pristine $\mathrm{C}_{6} \mathrm{BN}$ monolayers show a band gap, consistent with our previous discussion. After adsorption of $\mathrm{K}$ they turn metallic, because the electrons transferred from $\mathrm{K}$ partially occupy the 
conduction band (higher occupation when more $\mathrm{K}$ is adsorbed). Therefore, adsorption of $\mathrm{K}$ significantly improves the conductivity of the $\mathrm{C}_{6} \mathrm{BN}$ monolayers.

\section{CONCLUSION}

Motivated by recent synthesis of a $\mathrm{C}_{6} \mathrm{BN}$ monolayer, we predict two new $\mathrm{C}_{6} \mathrm{BN}$ monolayers. They likely can be synthesized by the same experimental method because of structural and energetic similarity combined with good dynamical, thermal, and mechanical stabilities. The $\mathrm{C}_{6} \mathrm{BN}$ monolayers exhibit in-plane stiffnesses comparable to that of graphene while providing enhanced flexibility, which makes them interesting for flexible devices. An investigation of $\mathrm{K}$ adsorption demonstrates high specific capacities and low average OCVs for K-ion battery anodes based on $\mathrm{C}_{6} \mathrm{BN}$ monolayers. Also, low $\mathrm{K}$ diffusion barriers point to excellent rate performance. The conductivity of the $\mathrm{C}_{6} \mathrm{BN}$ monolayers is significantly improved when $\mathrm{K}$ is adsorbed. Overall, our results indicate that $\mathrm{C}_{6} \mathrm{BN}$ monolayers are excellent candidate materials for anodes of $\mathrm{K}$-ion batteries, combining high specific capacity with low cost, high strength, excellent flexibility, low output voltage, excellent rate performance, and improved conductivity. This set of properties calls for experimental efforts to verify the predicted electrochemical performance of $\mathrm{C}_{6} \mathrm{BN}$ monolayers.

\section{ASSOCIATED CONTENT}

\section{SI Supporting Information}

The Supporting Information is available free of charge at https://pubs.acs.org/doi/10.1021/acsami.0c09451.

Structural details of the optimized $\mathrm{C}_{6} \mathrm{BN}$ nanotubes; total energy of $\mathrm{C}_{6} \mathrm{BN}$-I for different k-meshes; top and side views of the unit cells of $\mathrm{C}_{6} \mathrm{BN}-\mathrm{II}$ and $\mathrm{C}_{6} \mathrm{BN}-\mathrm{III}$; thermal stability of the $\mathrm{C}_{6} \mathrm{BN}$ monolayers at $1200 \mathrm{~K}$; intermediate structures during potassiation; maximally potassiated $\mathrm{C}_{6} \mathrm{BN}$ monolayers at $300 \mathrm{~K}(\mathrm{PDF})$

\section{AUTHOR INFORMATION}

\section{Corresponding Authors}

Sitansh Sharma - Physical Sciences and Engineering Division, King Abdullah University of Science and Technology, Thuwal 23955-6900, Saudi Arabia; Email: sitansh.sharma@ kaust.edu.sa

Jiang Wu - Institute of Fundamental and Frontier Sciences, University of Electronic Science and Technology of China, Chengdu 610054, P. R. China; (1) orcid.org/0000-0003-06796196; Email: jiangwu@uestc.edu.cn

Udo Schwingenschlögl - Physical Sciences and Engineering Division, King Abdullah University of Science and Technology, Thuwal 23955-6900, Saudi Arabia; 이이이.org/0000-00034179-7231; Email: udo.schwingenschlogl@kaust.edu.sa

\section{Authors}

Pan Xiang - Institute of Fundamental and Frontier Sciences, University of Electronic Science and Technology of China, Chengdu 610054, P. R. China; Physical Sciences and Engineering Division, King Abdullah University of Science and Technology, Thuwal 23955-6900, Saudi Arabia; ㅈorcid.org/ 0000-0003-3880-6221

Zhiming M. Wang - Institute of Fundamental and Frontier Sciences, University of Electronic Science and Technology of China, Chengdu 610054, P. R. China
Complete contact information is available at: https://pubs.acs.org/10.1021/acsami.0c09451

\section{Notes}

The authors declare no competing financial interest.

\section{ACKNOWLEDGMENTS}

The research reported in this publication was supported by funding from King Abdullah University of Science and Technology (KAUST). Computational resources were provided by the Supercomputing Laboratory of KAUST. We also acknowledge support by the National Key Research and Development Program of China (2019YFB2203400), the 111 Project (B20030), and the UESTC Shared Research Facilities of Electromagnetic Wave and Matter Interaction (Y0301901290100201)

\section{REFERENCES}

(1) Meier, P. J.; Wilson, P. P. H.; Kulcinski, G. L.; Denholm, P. L. US Electric Industry Response to Carbon Constraint: A Life-Sycle Assessment of Supply Side Alternatives. Energy Policy 2005, 33, 1099-1108.

(2) Larcher, D.; Tarascon, J. M. Towards Greener and More Sustainable Batteries for Electrical Energy Storage. Nat. Chem. 2015, 7, 19-29.

(3) Kousksou, T.; Bruel, P.; Jamil, A.; El Rhafiki, T.; Zeraouli, Y. Energy Storage: Applications and Challenges. Sol. Energy Mater. Sol. Cells 2014, 120, 59-80.

(4) Dunn, B.; Kamath, H.; Tarascon, J.-M. Electrical Energy Storage for the Grid: A Battery of Choices. Science 2011, 334, 928-935.

(5) Yang, Z.; Zhang, J.; Kintner-Meyer, M. C. W.; Lu, X.; Choi, D.; Lemmon, J. P.; Liu, J. Electrochemical Energy Storage for Green Grid. Chem. Rev. 2011, 111, 3577-3613.

(6) Mo, R.; Rooney, D.; Sun, K.; Yang, H. Y. 3D Nitrogen-Doped Graphene Foam with Encapsulated Germanium/Nitrogen-Doped Graphene Yolk-Shell Nanoarchitecture for High-Performance Flexible Li-Ion Battery. Nat. Commun. 2017, 8, 13949.

(7) Cano, Z. P.; Banham, D.; Ye, S.; Hintennach, A.; Lu, J.; Fowler, M.; Chen, Z. Batteries and Fuel Cells for Emerging Electric Vehicle Markets. Nature Energy 2018, 3, 279-289.

(8) Jia, J.; Li, B.; Duan, S.; Cui, Z.; Gao, H. Monolayer MBenes: Prediction of Anode Materials for High-Performance Lithium/ Sodium Ion Batteries. Nanoscale 2019, 11, 20307-20314.

(9) Cui, H.; Guo, Y.; Ma, W.; Zhou, Z. 2 D Materials for Electrochemical Energy Storage: Design, Preparation, and Application. ChemSusChem 2020, 13, 1155-1171.

(10) Gruber, P. W.; Medina, P. A.; Keoleian, G. A.; Kesler, S. E.; Everson, M. P.; Wallington, T. J. Global Lithium Availability. J. Ind. Ecol. 2011, 15, 760-775.

(11) Yabuuchi, N.; Kubota, K.; Dahbi, M.; Komaba, S. Research Development on Sodium-Ion Batteries. Chem. Rev. 2014, 114, 11636-11682.

(12) Kim, H.; Kim, J. C.; Bianchini, M.; Seo, D.-H.; RodriguezGarcia, J.; Ceder, G. Recent Progress and Perspective in Electrode Materials for K-Ion Batteries. Adv. Energy Mater. 2018, 8, 1702384.

(13) Zhang, W.; Liu, Y.; Guo, Z. Approaching High-Performance Potassium-Ion Batteries Via Advanced Design Strategies and Engineering. Science Advances 2019, 5, eaav7412.

(14) Jian, Z.; Xing, Z.; Bommier, C.; Li, Z.; Ji, X. Hard Carbon Microspheres: Potassium-Ion Anode Versus Sodium-Ion Anode. Adv. Energy Mater. 2016, 6, 1501874.

(15) Luo, W.; Wan, J.; Ozdemir, B.; Bao, W.; Chen, Y.; Dai, J.; Lin, H.; Xu, Y.; Gu, F.; Barone, V.; Hu, L. Potassium Ion Batteries with Graphitic Materials. Nano Lett. 2015, 15, 7671-7677.

(16) Yang, J.; Yuan, Y.; Chen, G. First-Principles Study of Potassium Adsorption and Diffusion on Graphene. Mol. Phys. 2020, 118, No. e1581291. 
(17) Joshi, R. P.; Ozdemir, B.; Barone, V.; Peralta, J. E. Hexagonal $\mathrm{BC}_{3}$ : A Robust Electrode Material for $\mathrm{Li}, \mathrm{Na}$, and $\mathrm{K}$ Ion Batteries. J. Phys. Chem. Lett. 2015, 6, 2728-2732.

(18) Bhauriyal, P.; Mahata, A.; Pathak, B. Graphene-Like CarbonNitride Monolayer: A Potential Anode Material for $\mathrm{Na}$ - and K-Ion Batteries. J. Phys. Chem. C 2018, 122, 2481-2489.

(19) Sen, S.; Moses, K.; Bhattacharyya, A. J.; Rao, C. N. R. Excellent Performance of Few-Layer Borocarbonitrides as Anode Materials in Lithium-Ion Batteries. Chem. - Asian J. 2014, 9, 100-103.

(20) Matsui, K.; Oda, S.; Yoshiura, K.; Nakajima, K.; Yasuda, N.; Hatakeyama, T. One-Shot Multiple Borylation toward BN-Doped Nanographenes. J. Am. Chem. Soc. 2018, 140, 1195-1198.

(21) Liu, X.; Ma, X.; Gao, H.; Zhang, X.; Ai, H.; Li, W.; Zhao, M. Valley-Selective Circular Dichroism and High Carrier Mobility of Graphene-Like $\mathrm{BC}_{6} \mathrm{~N}$. Nanoscale 2018, 10, 13179-13186.

(22) Rao, C. N. R.; Gopalakrishnan, K. Borocarbonitrides, $B_{x} C_{y} N_{z}$ : Synthesis, Characterization, and Properties with Potential Applications. ACS Appl. Mater. Interfaces 2017, 9, 19478-19494.

(23) Rao, C. N. R.; Pramoda, K. Borocarbonitrides, $\mathrm{B}_{\mathrm{x}} \mathrm{C}_{\mathrm{y}} \mathrm{N}_{z}, 2 \mathrm{D}$ Nanocomposites with Novel Properties. Bull. Chem. Soc. Jpn. 2019, $92,441-468$.

(24) Delley, B. An All-Electron Numerical-Method for Solving the Local Density Functional for Polyatomic-Molecules. J. Chem. Phys. 1990, 92, 508-517.

(25) Delley, B. From Molecules to Solids with the DMol3 Approach. J. Chem. Phys. 2000, 113, 7756-7764.

(26) Grimme, S. Semiempirical GGA-Type Density Functional Constructed with a Long-Range Dispersion Correction. J. Comput. Chem. 2006, 27, 1787-1799.

(27) Togo, A.; Tanaka, I. First Principles Phonon Calculations in Materials Science. Scr. Mater. 2015, 108, 1-5.

(28) Kresse, G.; Joubert, D. From Ultrasoft Pseudopotentials to the Projector Augmented-Wave Method. Phys. Rev. B: Condens. Matter Mater. Phys. 1999, 59, 1758-1775.

(29) Clark, S. J.; Segall, M. D.; Pickard, C. J.; Hasnip, P. J.; Probert, M. J.; Refson, K.; Payne, M. C. First Principles Methods Using CASTEP. Z. Kristallogr. - Cryst. Mater. 2005, 220, 567-570.

(30) Nozaki, H.; Itoh, S. Structural Stability of $\mathrm{BC}_{2} \mathrm{~N}$. J. Phys. Chem. Solids 1996, 57, 41-49.

(31) Qin, Z.; Qin, G.; Hu, M. Origin of Anisotropic Negative Poisson's Ratio in Graphene. Nanoscale 2018, 10, 10365-10370.

(32) Wang, H.; Li, Q.; Pan, H.; Gao, Y.; Sun, M. Comparative Investigation of the Mechanical, Electrical and Thermal Transport Properties in Graphene-Like $\mathrm{C}_{3} \mathrm{~B}$ and $\mathrm{C}_{3}$ N. J. Appl. Phys. 2019, 126, 234302.

(33) Mouhat, F.; Coudert, F.-X. Necessary and Sufficient Elastic Stability Conditions in Various Crystal Systems. Phys. Rev. B: Condens. Matter Mater. Phys. 2014, 90, 224104.

(34) Cadelano, E.; Palla, P. L.; Giordano, S.; Colombo, L. Elastic Properties of Hydrogenated Graphene. Phys. Rev. B: Condens. Matter Mater. Phys. 2010, 82, 235414.

(35) Wei, Y.; Wang, B.; Wu, J.; Yang, R.; Dunn, M. L. Bending Rigidity and Gaussian Bending Stiffness of Single-Layered Graphene. Nano Lett. 2013, 13, 26-30.

(36) Zou, X.; Liu, Y.; Yakobson, B. I. Predicting Dislocations and Grain Boundaries in Two-Dimensional Metal-Disulfides from the First Principles. Nano Lett. 2013, 13, 253-258.

(37) Toyoura, K.; Koyama, Y.; Kuwabara, A.; Oba, F.; Tanaka, I. First-Principles Approach to Chemical Diffusion of Lithium Atoms in a Graphite Intercalation Compound. Phys. Rev. B: Condens. Matter Mater. Phys. 2008, 78, 214303.

(38) Ganesh, P.; Kim, J.; Park, C.; Yoon, M.; Reboredo, F. A.; Kent, P. R. C. Binding and Diffusion of Lithium in Graphite: Quantum Monte Carlo Benchmarks and Validation of Van Der Waals Density Functional Methods. J. Chem. Theory Comput. 2014, 10, 5318-5323.

(39) Jena, N. K.; Araujo, R. B.; Shukla, V.; Ahuja, R. Borophane as a Benchmate of Graphene: A Potential 2D Material for Anode of Li and Na-Ion Batteries. ACS Appl. Mater. Interfaces 2017, 9, 16148-16158.
(40) Eftekhari, A. Low Voltage Anode Materials for Lithium-Ion Batteries. Energy Storage Materials 2017, 7, 157-180.

(41) Er, D.; Li, J.; Naguib, M.; Gogotsi, Y.; Shenoy, V. B. $\mathrm{Ti}_{3} \mathrm{C}_{2}$ MXene as a High Capacity Electrode Material for Metal ( $\mathrm{Li}, \mathrm{Na}, \mathrm{K}$, Ca) Ion Batteries. ACS Appl. Mater. Interfaces 2014, 6, 11173-11179.

(42) Zhang, X.; Yu, Z.; Wang, S.-S.; Guan, S.; Yang, H. Y.; Yao, Y.; Yang, S. A. Theoretical Prediction of $\mathrm{MoN}_{2}$ Monolayer as a High Capacity Electrode Material for Metal Ion Batteries. J. Mater. Chem. A 2016, 4, 15224-15231.

(43) Sibari, A.; Kerrami, Z.; Kara, A.; Hamedoun, M.; Benyoussef, A.; Mounkachi, O.; Benaissa, M. Adsorption and Diffusion on a Phosphorene Monolayer: A DFT Study. J. Solid State Electrochem. 2018, 22, 11-16. 